\title{
PEMETAAN DAERAH RAWAN BANJIR BERBASIS SISTEM INFORMASI GEOGRAFIS (GIS) DI PESISIR DANAU TEMPE KABUPATEN WAJO
} Mukti Ali ${ }^{1}$, S. Trisutomo ${ }^{2}$, Sri Aliah Ekawati ${ }^{2}$, Resti Kharisma ${ }^{3}$, A. Arlyn Avila ${ }^{3}$, S.A Ikke P ${ }^{3}$, A. Risdayanti ${ }^{3}$, Arman $\mathbf{M}^{3}$

${ }^{1}$ Labo Perencanaan dan Pengembangan Wil. Pesisir, Fakultas Teknik, Universitas Hasanuddin ${ }^{2}$ Labo Perencanaan dan Pengembangan Wil. Pesisir, Fakultas Teknik, Universitas Hasanuddin

${ }^{3}$ Anggota Labo Perencanaan dan Pengembangan Wil. Pesisir, Fakultas Teknik, Universitas Hasanuddin

\begin{abstract}
Intisari
Salah satu daerah di Indonesia yang rawan banjir pada waktu musim penghujan adalah Kabupaten Wajo Provinsi Sulawesi Selatan. Banjir yang terjadi disebabkan oleh meluapnya air dari Danau Tempe akibat Sungai Walanae, Sungai Bila, Sungai Belokka, Sungai Batu-batu dan Sungai Lawo yang membawa sedimentasi dari daerah hulu kemudian bermuara di Danau Tempe. Banjir yang hampir terjadi setiap tahunnya tersebut, menyebabkan kerugian materil maupun non-materil bagi masyarakat utamanya yang berada di wilayah sekitar Danau Tempe. Selain itu, belum adanya pemetaan secara menyeluruh terkait mitigasi bencana banjir di Pesisir Danau Tempe. Tujuan dari penelitian ini adalah pemetaan daerah rawan banjir di Pesisir Danau Tempe Kabupaten Wajo berbasis sistem informasi geografis. Metode pencapaian target luaran disusun berdasarkan proses perencanaan konsep dan arahan. Perencanaan dijabarkan/implementasikan pada konsep-kosep kemitigasi-bencanaan sehingga menghasilkan sebuah arahan atau kebijakan untuk mitigasi bencana banjir di pesisir Danau Tempe Kabupaten Wajo. Konsep perencanaan ini di hasilkan dari proses penelitian dimulai dari identifikasi masalah, survei baik secara primer dan sekunder, kegiatan analisis data - kajian teori, dan keluaran berupa arahan kebijakan.
\end{abstract}

Kata kunci: Mitigasi Bencana, Banjir, GIS, Danau Tempe

\begin{abstract}
One of the areas in Indonesia that are prone to flooding in the wet season is Wajo Regency of South Sulawesi province. Flooding caused by the frequent of water from Tempe Lake due to Walanae River, Belokka River, Bila River, Batu-batu River and Lawo River which brought the sedimentation upstream then empties in Tempe Lake. The flooding that almost occurred every year, caused losses of material or non-material for the main community located around the Tempe Lake. In addition, it has not been thoroughly mapping the presence of associated mitigation of coastal in the Lake Tempe. The purpose of this research is mapping the area prone to flooding in Coastal Tempe Lake, Wajo Regency based on geographic information system. A method of target achievement external structured planning process concept and direction. Planning elaborated on the concepts implemented/concept of mitigation so that it generates a referral or a policy for mitigation of coastal flooding in the Tempe Lake, Wajo Regency. This planning concept in the produce of the process starts from the identification of the research problem, the survey of the primary and secondary data analysis, activity analysis theory, and output in the form of referral policy.
\end{abstract}

Keywords: disaster mitigation, flood, GIS, Tempe lake

\section{PENDAHULUAN}

Salah satu daerah di Indonesia yang rawan banjir pada waktu musim penghujan adalah Kabupaten Wajo Provinsi Sulawesi Selatan. Banjir yang tejadi di daerah tersebut menyebabkan terjadinya genangan. Genangan banjir yang terjadi disebabkan oleh meluapnya Danau Tempe akibat sungai Walanae, sungai Bila, sungai Belokka, sungai Batu-batu dan sungai Lawo yang membawa sedimentasi dari daerah hulu kemudian bermuara di Danau Tempe. Dengan demikian terjadi pendangkalan pada dasar danau tersebut (www.inawater.com).

Beberapa isu terkait permasalahan banjir di Danau Tempe:
- Dalam beberapa tahun terakhir, kondisi perairan Danau Tempe telah mengalami perubahan antara lain sebagian dari wilayah danau telah menjadi daratan.

- Terjadinya akumulasi sedimen yang dibawa oleh aliran air menjadikan Danau Tempe semakin dangkal yang mengakibatkan daya tampung volume air menjadi berkurang. Total sedimen yang masuk yakni $1.069 .099 \mathrm{~m}^{3}$ sementara yang dikeluarkan melalui Sungai Cendranae adalah $550.490 \mathrm{~m}^{3}$. Dengan demikian, sisa sedimen yang mengendap di dsar danu sebesar $510.609 \mathrm{~m}^{3}$. ${ }^{(1)}$ 
- Berdasarkan PPSP (Program Percepatan Pembangunan Sanitasi Permukiman) Kabupaten Wajo 2014 menunjukkan bahwa kondisi wilayah Kabupaten Wajo yang berbentuk mangkok menyebabkan aliran air dari berbagai kabupaten lain seperti Soppeng, Bone, Luwu dan lain-lain akan berhulu ke Kabupaten Wajo. Hal ini menyebabkan banjir karena melupanya Danau Tempe dan ditambah dengan banyaknya saluran drainase yang tidak berfungsi dengan baik, sungai yang mengalami pendangkalan.

- Adanya alih fungsi lahan dari hutan menjadi areal pertanian dan areal pertanian menjadi non pertanian akan menyebabkan terjadinya peningkatan erosi permukaan pada tahap awalnya. Selanjutnya tanah yang tererosi tersebut akan terbawa ke sungai dan menyebabkan laju sedimentasi DAS meningkat.

- Penyelenggaraan penanggulangan bencana di Kabupaten Wajo perlu ditingkatkan dengan melakukan perubahan cara pandang bencana dari yang bersifat tanggap darurat menjadi pengurangan risiko bencana. Hal ini dilakukan sebagai upaya yang lebih menyeluruh terkait dengan penanggulangan bencana. Salah satu upaya tersebut di tingkat pemerintahan, ditandai dengan masuknya penanganan dan pengurangan risiko bencana sebagai salah satu agenda pembangunan Kabupaten Wajo Tahun 20082013 dalam Rencana Pembangunan Jangka Menengah (RPJM) Kabupaten Wajo. (Rencana Penanggulangan Kabupaten Wajo, 2012). ${ }^{(2)}$

- Banjir yang hampir terjadi setiap tahunnya tersebut menyebabkan kerugian materil maupun non-materil bagi masyarakat utamanya yang berada di wilayah sekitar Danau Tempe. Adapun kecamatan yang paling rawan yakni Kecamatan Tempe, Pammana, Sabbangparu, dan Takkalalla (BMKG, 2014) dikarenakan termasuk dalam kecamatan dengan daftar curah hujan yang tinggi.

Dengan berbagai isu dan persoalan terkait banjir tersebut, maka dalam penelitian ini difokuskan pada pemetaan daerah rawan banjir berbasis Sistem Informasi Geografis (SIG) di pesisir Danau Tempe Kabupaten Wajo.

\section{ISI PENELITIAN}

\subsection{Metode}

Jenis penelitian yang digunakan adalah penelitian deskriptif dengan pendekatan kualitatif.

Jenis data terbagi menjadi dua yaitu data primer dan sekunder. Data primer diperoleh secara langsung dengan melakukan observasi di lapangan serta wawancara langsung yang berhubungan dengan data-data yang dibutuhkan berupa data tentang banjir, guna lahan dan lain sebagainya. Data Sekunder, diperoleh dari kantor instansi terkait (dokumentasi) yang mengetahui fisik lingkungan berupa topografi kawasan, serta referensi-referensi lainya yang relevan dengan masalah pokok dalam penelitian ini.

Teknik analisis yang digunakan dalam penelitian adalah sebagai berikut:

2.1.1 Analisis deskriptif kualitatif, digunakan untuk mengetahui karakteristik pola penggunaan lahan kawasan pesisir Danau Tempe.

2.1.2 Analisis Spasial

Analisis spasial merupakan analisis keruangan menggunakan data yang diinterpretasikan dalam bentuk peta. Analisis ini menggunakan alat bantu software terutama ArcGIS. Dalam penelitian ini, terdapat dua jenis spasial yang digunakan yakni spasial pemetaan dan spasial overlay. Spasial pemetaan merupakan penggambaran kondisi eksisting ke dalam peta, sedangkan spasial overlay merupakan analisis beberapa peta untuk menghasilkan peta baru, sehingga menghasilkan peta rawan banjir. ${ }^{(3)}$

2.1.3 Perpaduan antara analisis skoring dan analisis overlay. Tahap awal dilakukan analisis skoring untuk menghasilkan jalur evakuasi dan titik evakuasi. Dari hasil ini, diperoleh rencana tindakan berupa peringatan dini untuk bencana banjir di Pesisir Danau Tempe.

\subsection{Hasil dan Pembahasan \\ 2.2.1 Tinjauan Wilayah Danau Tempe}

Danau Tempe adalah salah satu danau besar yang terletak di Propinsi Sulawesi Selatan, tepatnya di Kabupaten Wajo (70\%), Kabupaten Sidrap dan Kabupaten Soppeng. Danau ini melintasi 10 Kecamatan dan 51 desa. Danau Tempe yang terbentuk dari depresi lempeng bumi Asia-Australia ini terletak di Wilayah Sungai Walannae Cenranae dan memiliki luas 47.800 ha pada ketinggian $10 \mathrm{~m}$ dpl dengan luas daerah tangkapan air (catchment area) Danau Tempe seluas $4.587 \mathrm{~km} 2$. Curah hujan tahunan di daerah danau sebesar $1.800 \mathrm{~mm} / \mathrm{th}$ sedangkan di daerah DAS sebesar $4.000 \mathrm{~mm} / \mathrm{th}$. Tinggi muka air (TMA) Danau Tempe hingga tahun 2001 menunjukkan kondisi yang normal, dengan TMA rata-rata berada pada kisaran 4,078 m sampai 7,780 m dpl. Kedalaman danau saat ini $3 \mathrm{~m}$ ketika musim hujan dan $1 \mathrm{~m}$ ketika musim kering. Luas permukaan danau pada musim hujan adalah 48.000 ha dan menggenangi areal persawahan, perkebunan, rumah penduduk, prasarana jalan dan jembatan serta prasarana sosial lainnya yang menimbulkan kerugian yang cukup besar. Pada musim kering luas danau hanya mencapai 1.000 ha sedangkan pada kondisi normal luasnya mencapai 15.000-20.000 ha. Sungai yang menuju ke danau terdiri dari 23 sungai yang 
termasuk dalam 2 DAS yaitu Das Bila dan DAS Walanae, sedangkan aliran sungai dari danau (outlet) hanya satu yaitu Sungai Cenranae yang memiliki panjang sungai $70 \mathrm{~km} .{ }^{(4)}$

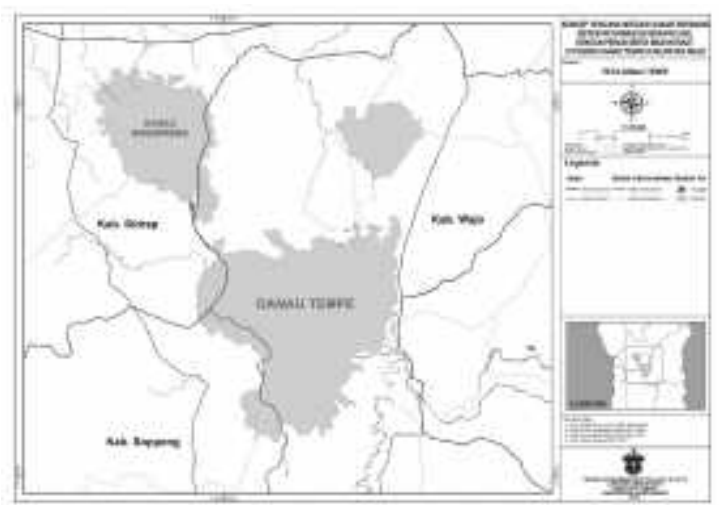

Gambar 1. Peta Lokasi Danau Tempe

\subsubsection{Lokasi Daerah Rawan Banjir}

Lokasi rawan banjir di Kecamatan Tempe terdapat di 10 Kelurahan yang berada di pesisir danau Tempe dan Sungai Cendrana merupakan satusatunya sungai yang mengalirkan air danau Tempe keluar ke laut (Teluk Bone).

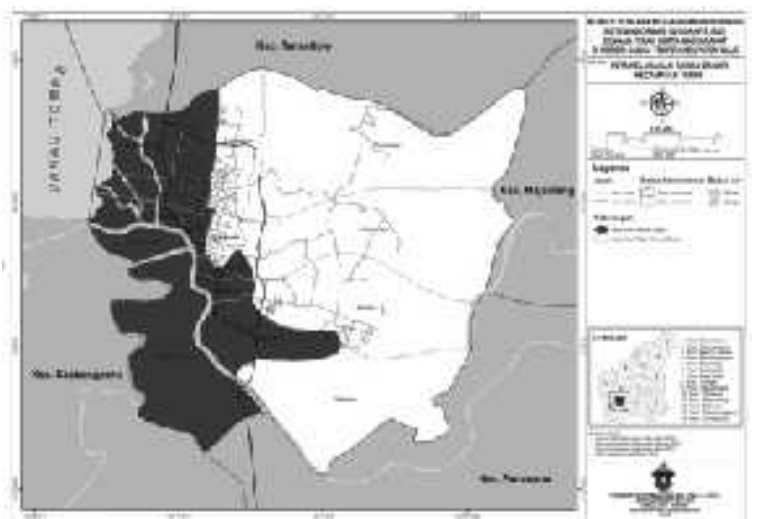

Gambar 2. Peta Kelurahan Rawan Banjir di Kecamatan Tempe

Berikut Kelurahan yang berada dipesisir danau Tempe dan sungai Cendrana:

- Kelurahan Mattirotappereng

- Kelurahan Tempe

- Kelurahan Watanglipue

- Kelurahan Laelo

- Kelurahan Salomenraleng

- Kelurahan Teddaopu

- Kelurahan Wiringpalennae

- Kelurahan Paddupa

- Kelurahan Siengkang

- Kelurahan Maddukeleng

Dari sepuluh Kelurahan yang terdampak banjir terdapat empat Kelurahan yang berbatasan langsung dengan danau Tempe dan enam Kelurahan yang dilalui oleh sungai Cendrana. Empat Kelurahan yang berbatasan lansung dengan danau Tempe merupakan
Kelurahan yang terletak di Timur Kecamatan Tempe.

\subsubsection{Deliniasi Kawasan}

Perencanaan mitigasi pada Kecamatan Tempe di fokuskan pada lima Kelurahan terdapat parah utamanya di kawasan pemukiman. Kelima Kelurahan tersebut adalah Kelurahan Mattirotappareng, Kelurahan Tempe, Kelurahan Laelo, Kelurahan Watanglipue dan Kelurahan Salomendraleng.

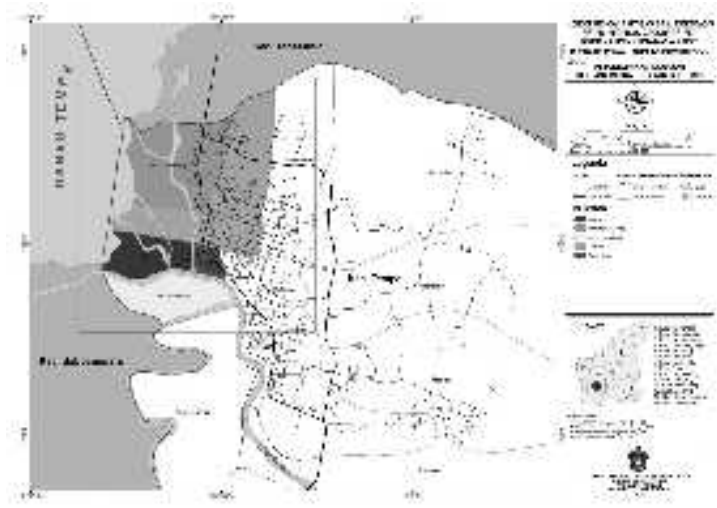

Gambar 3. Peta Deliminasi Kawasan Rencana Mitigasi Kecamatan Tempe

Kelima Kelurahan tersebut telah menjadi kelurahan langganan banjir utamanya pada bagian Timur Kelurahan (bagian dekat danau). Kelurahan yang tersebut memiliki kontur rendah pada bagian Timur dan tinggi di bagian Barat.

\subsubsection{Faktor Penyebab Banjir di Kecamatan Tempe}

Pada dasarnya banjir yang terjadi di Kecamatan Tempe disebabkan oleh luapan air dari danau Tempe. Meluapnya air danau Tempe di sebabkan oleh faktor-faktor berikut:

- Pendangkalan Danau Tempe

Danau Tempe dari tahun ketahun terus mengalami pendakalan yang disebabkan oleh sedimentasi pada dasar danau Tempe. Sedimentasi disebabkan oleh terbawanya meteial tanah dan pasir oleh air akibat gundulnya hutan di bagian hulu.

- Curah hujan yang tinggi

Pada musim penghujan Kabupaten Wajo utamanya Kecamatan Tempe megalami intensitas hujan yang cukup tinggi. Curah hujan yang tinggi mengakibatkan jumlah air yang di tampung Danau Tempe meningkat. Peningkatan voleme air di danau menyebakan luapan ke daerah sekitarnya termasuk Kecamatan Tempe yang berbatasan langsung Danau Tempe.

- Tingginya volume air yang masuk ke Danau Tempe

Di Danau Tempe terdapat sembilan sungai yang mengalir dari berbagai daerah. Dari kesembilan 
sungai yang masuk ke danau terdapat delapan sungai yang mengalirkan air dari berbagai daerah masuk ke Danau Tempe. Untuk satu sungai lainnya menrupakan sungai yang mengalirkan air keluar dari danau menuju Teluk Bone.

Banyaknya sungai di berbagai daerah sekitar Danau Tempe yang masuk ke danau akan mengakibatkan danau meluap bila terjadi hujan deras di daerah hulu sungai. Meluapnya Danau Tempe terkadang tidak disebabkan hujan yang terjadi di Kabupaten Wajo melainkan hujan deras yang terjadi pada hulu sungai di berbagai daerah sekitar.

\subsubsection{Kondisi Banjir pada Kawasan Rencana Mitigasi}

Danau Tempe pada saat musim penghujan akan meluap dan mengenangi daerah sekitar. Kecamatan Tempe yang merupakan salah satu daerah langganan luapan air Danau Tempe. Luapan Danau Tempe terjadi pada bulan Mei hingga bulan Juli.

Banjir pada Kecamatan Tempe merendam kebun dan beberapa rumah warga. Setiap tahunnya dibulan Mei hinga bulan Agustus kolong rumah warga yang merupakan rumah panggung terendam banjir. Warga Kelurahan Mattirotappareng, Kelurahan Tempe dan Kelurahan Watallipue telah mengetahui bahwa sebagian wilayah Kelurahan mereka adalah daerah langganan banjir. Untuk Kelurahan Laelo dan Kelurahan Salomenraleng merupakan Kelurahan yang terparah mengalami banjir.banjir di Kelurahan Laelo dan Salomenraleng biasa mencapai 3,5 meter. Berikut peta genangan banjir di kawasa recana mitigasi.

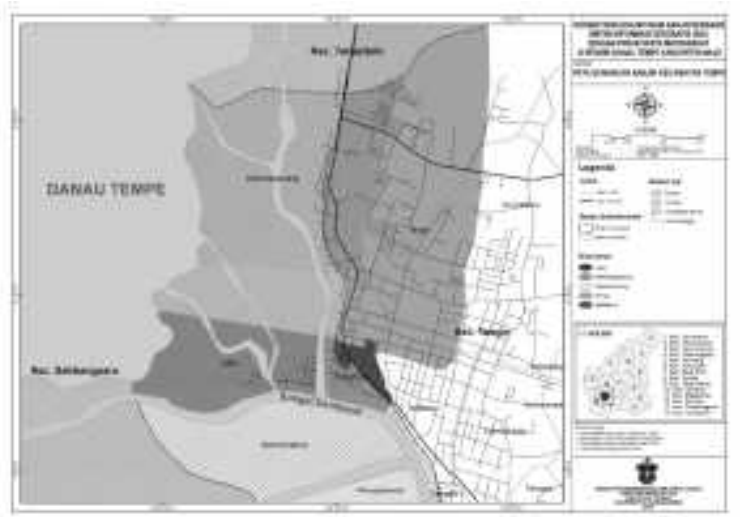

Gambar 4. Peta Genangan Banjir di Kecamatan Tempe

Pada peta genangan banjir di 5 Kelurahan terlihat bahwa banjir terjadi pada bagian Timur dari jalan. Banjir yang tersebut hanya terjadi di Timur jalan dan tidak menggenangi jalan Budi Utomo dan jalan Andi Ninnong ke bagian Barat sebab jalan tersebut memiliki kontur yang lebih tinggi. Dari peta genangan banjir maka dapat dilihat bahwa
Kelurahan Laelo dan Kelurahan Salonmenraleng megalami banjir di seluruh wilayahnya. Akibat dari banjir yang merendam seluruh Kelurahan Laelo dan kelurahan Salomenraleng ketikan air danau meluap maka sarana publik berupa rumah ibadah, sekolah dan Kantor Kelurahan dibuat bertingkat atau panggung.

\subsubsection{Karakteristik Kerentanan Daerah Rawan Banjir di Danau Tempe}

Danau Tempe secara topografi dan hidrologi tidak terpisah dari 2 (dua) danau di sekitarnya yaitu Danau Sidenreng dan Danau Buaya yang mempunyai daerah pengaliran sungai seluas 6.138 $\mathrm{Km}^{2}$, secara kliminologi dan ekologi, danau ini termasuk tipe danau entropies, yaitu berbentuk cawan yang sangat datar dengan karakteristik tersedianya lahan pasang surut luas di sekitar danau. Pada umumnya Danau Tempe dalam setahun dapat menutupi areal seluas 10.000 ha dan pada musim kemarau dapat menurun menjadi 1000 ha.

Fluktuasi ketinggian air pada saat banjir mencapai sekitar 2 sampai 4 meter, sementara kedalaman danau hanya 5 sampai 7 meter. Banjir oleh kiriman dari daerah sekitarnya, yang sungainya bermuara ke Danau Tempe, sedangkan saluran pembuangan hanya satu yaitu sungai Cendranae yang bermuara di Teluk Bone. Untuk Kabupaten Wajo, Sidrap, dan Soppeng, danau tersebut merupakan kantong air. Sumber air untuk danau ini berasal dari dua sungai besar yaitu Sungai Bila dari Pegunungan Latimojong dan Sungai Walannae dari Pegunungan Lompobattang, dan sungai-sungai kecil seperti Sungai Kalola, Sungai Lanciran, dan Sungai Batu-batu.

Karaktersitik Danau Tempe dengan kondisi banjir yang selalu terjadi setiap tahun pada musim hujan dapat dilihat pada keadaan danau dengan elevasi yang landai sehingga volume air yang bertambah melalui sungai akan meluap dan menyebabkan banjir. Iklim tropis serta curah hujan tinggi di sepanjang sungai yang bermuara di danau merupakan kondisi yang menyebabkan besarnya volume air yang tertampung dalam danau. Berdasarkan data Stasiun Klimatologi bahwa daerah Danau Tempe dan sekitarnya termasuk dalam wilayah iklim tropik basah, yang dicirikan dengan adanya dua musim yaitu musim hujan dan musim kemarau. Musim hujan terjadi pada bulan Februari sampai Juli, November dan Desember, sedangkan musim kemarau terjadi pada bulan Agustus sampai Oktober dan Januari.

\subsubsection{Rencana Titik Evakuasi Bencana Banjir di Pesisir Danau Tempe}

Titik evakuasi merupakan titik yang sangat penting saat bencana terjadi. Titik ini merupakan titik untuk menampung warga yang terdapak banjir. 
Dengan adanya titik evakuasi akan membuat warga mengetahui harus kemana saat bencana banjir terjadi. Titik evakuasi harus mampu menampung warga yang terdapak oleh banjir, oleh karena itu titik evakuasi harus berada pada ruang terbuka yang luas dan mudah di jangkau.

Untuk mengantisipasi banjir yang terjadi di Kecamatan Tempe maka harus ditetapkan titik evakuasi warga yang terdampak oleh banjir. Titik evakuasi di Kecamatan Tempe dapat di tetapkan pada 2 lokasi yaitu Lapangan Merdeka dan lahan SPBU yang sudah tidak beroprasi di kelurahan Mattirotappareng. Berikut peta perencanaan titik evakuasi di Kecamatan Tempe.

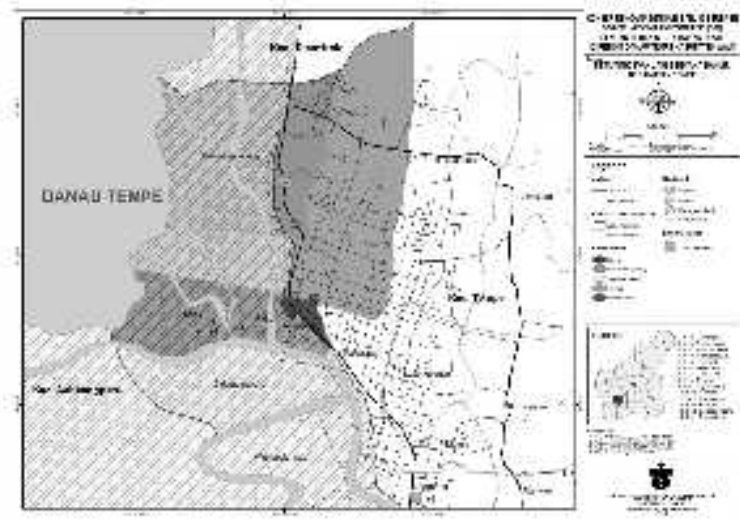

Gambar 5. Peta Rencana Titik Evakuasi Bencana Banjir Kecamatan Tempe

Pada titik evakuasi yang telah di tentukan juga harus didirikan tenda pengungsian yang kondisinya baik sehingga korban banjir dapat menetap sementara sampai air surut. Selain itu pada titik evakuasi juga harus di sediakan posko dan tenaga kesehatan yang dapat mengobati penyakit warga akibat banjir yang terjadi.

\subsubsection{Rencana Jalur Evakuasi Bencana Banjir Danau Tempe}

Jalur evakuasi adalah akses warga yang terdampak banjir untuk pergi ke titik evakuasi. Jalur evakuasi merupakan jalur yang harus di ketahui warga ketika banjir terjadi. Penentuan jalur evakuasi akan memperjelas alur warga ketika hendak menyelamatkan diri ke titik evakuasi yang telah di tentukan.

Pada Kecamatan Tempe banjir terjadi pada kelurahan yang berbatasan dengan Danau Tempe atau bagian Barat Kecamatan Tempe. Jadi jalur evakuasi mengarah ke Timur hingga menjacapai jalan utama yang memiliki elavasi yang lebih tinggi. Ketika telah berada di jalan utama maka warga yang memiliki kedaran dapat langsung mengarah ke titik evakuasi, namun bagi warga yang tidak memiliiki kendaraan dapat mengunakan aangkutan umum yang melali akses jalan utama atau menggu bantuan kendaraan bantuan pemerintah.

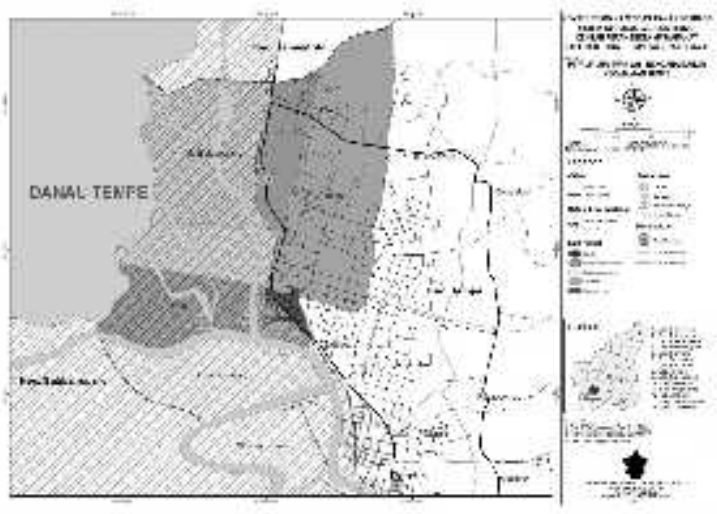

Gambar 6. Peta Rencana Jalur Evakuasi Banjir di Kecamatan Tempe

\subsubsection{Rencana Peringatan Dini Bencana Banjir Danau Tempe}

Peringatan dini adalah langkah utama yang harus dilakukan untuk mencegah jatuhnya korban. Degan adanya peringatan dini kewaspadaan warga akan meningkat. Peringatan dini sangat perlu untuk mempersiapkan warga dalam menyusun langkahlangkah yang akan diambil ketika banjir mengenangi rumah warga. Selain itu peringatan dini juga membantu warga dalam mempersiapkan diri untuk mengevakuasi diri mereka.

Peringatan dini harus dilakukan pemerintah dan pihak-pihak terkait sehingga warga dapat lebih tanggap ketika banjir akan terjadi. Pringatan dini dapat di lakukan dengan pengumuman melalui pembesar suara yang ada di masjid ataupun berkeliling ke daerah yang akan terdapak banjir mengunakan mobil yang di lengkapi dengan pembesar suara. Peringatan dini juga dapat dilakukan dengan pengumuman yang disampaikan melalui sairan radio dan juga pemanfaatan internet berupa website pemerintah dan juga pada jejaring sosial.

\section{KESIMPULAN}

Lokasi rawan banjir di Kecamatan Tempe Kabupaten Wajo terdapat di 10 Kelurahan, tetapi perencanaan mitigasi pada Kecamatan Tempe di fokuskan pada lima Kelurahan terdapat parah utamanya di kawasan pemukiman. Kelima Kelurahan tersebut adalah Kelurahan Mattirotappareng, Kelurahan Tempe, Kelurahan Laelo, Kelurahan Watanglipue dan Kelurahan Salomendraleng. Kelima Kelurahan tersebut telah menjadi kelurahan langganan banjir utamanya pada bagian Timur Kelurahan (bagian dekat danau). Kelurahan yang tersebut memiliki kontur rendah pada bagian Timur dan tinggi di bagian Barat.

Pada dasarnya banjir yang terjadi di Kecamatan Tempe disebabkan oleh luapan air dari danau Tempe. Meluapnya air danau Tempe di sebabkan oleh faktor-faktor seperti pendangkalan Danau 
Tempe, curah hujan tinggi dan tingginya volume air yang masuk ke danau. Fluktuasi ketinggian air pada saat banjir mencapai sekitar 2 sampai 4 meter, sementara kedalaman danau hanya 5 sampai 7 meter.

Titik evakuasi di Kecamatan Tempe dapat di tetapkan pada 2 lokasi yaitu Lapangan Merdeka dan lahan SPBU yang sudah tidak beroprasi di kelurahan Mattirotappareng.

Pada Kecamatan Tempe banjir terjadi pada kelurahan yang berbatasan dengan Danau Tempe atau bagian Barat Kecamatan Tempe. Jadi jalur evakuasi mengarah ke Timur hingga menjacapai jalan utama yang memiliki elavasi yang lebih tinggi.

Selain itu terdapat pula rencana peringatan dini yang harus dilakukan pemerintah dan pihak-pihak terkait sehingga warga dapat lebih tanggap ketika banjir akan terjadi. Pringatan dini dapat di lakukan dengan pengumuman melalui pembesar suara yang ada di masjid ataupun berkeliling ke daerah yang akan terdapak banjir mengunakan mobil yang di lengkapi dengan pembesar suara. Peringatan dini juga dapat dilakukan dengan pengumuman yang disampaikan melalui sairan radio dan juga pemanfaatan internet berupa website pemerintah dan juga pada jejaring sosial.

\section{DAFTAR PUSTAKA}

Amin, M dan Mustafa, A. 2000. Kualitas air Danau Tempe pada saat air naik dan surut, hal. 183-198. Dalam Prosiding Semiloka Nasional Pengelolaan dan Pemanfaatan Danau dan Waduk. Jurusan Perikanan Fakultas Pertanian Universitas Padjadjaran, Bandung.

Badan Penanggulangan Bencana Daerah, 2012. "Rencana Penanggulangan Bencana Kabupaten Wajo Sulawesi Selatan”.

Prahasta, Eddy. 2008. Remote Sensing : Praktis Penginderaan Jauh \& Pengolahan Citra Digital dengan Perangkat Lunak ER Mapper. Bandung: Penerbit Informatika.

Yusuf , M. 2011. http://www.kondisi-umum-danautempe dapus.html. 